\title{
Pengembangan cetak kemasan melalui keterampilan cetak sablon dan vacuum forming
}

\author{
Dian Cahyadi ${ }^{1}$, Lanta L. ${ }^{2}$ \\ ${ }^{1,2}$ Fakultas Seni dan Desain, Universitas Negeri Makassar
}

\begin{abstract}
The partner of this Community Partnership Program (PKM) was a student and teacher of YYPP SMK Wonomulyo Distric of Polewali Mandar of Sulawesi Barat Province. The problems were: (1) lack of knowledge about screen printing and heat molding wrapper so it has an attractive appearance, (2) easy to print screen printing and heat-forming packaging, (3) packaging products IRT / SME, and (4) the quality of the packaging print production sellable. External target is the SME / Industry Households have an interesting product packaging. The methods used are: lectures, demonstrations, discussions, question and answer, and counterparts. The results obtained are: (1) The partners have the skills to print T-shirts, (2) partners have the skills to print T-shirts, (3) the partner has the ability to produce attractive packaging
\end{abstract}

Keywords: printing, screen printing, packaging

\section{PENDAHULUAN}

Program Kemitraan Masyarakat (PKM) yang telah dilaksanakan bermitra dengan Pelajar dan Guru SMK YYPP Wonomulyo Kabupaten Polewali Mandar Propinsi Sulawesi Barat. Dinas Perindustrian Perdagangan, Koperasi dan Usaha Kecil Menengah (Disperindagkop dan UKM) terus melakukan pembenahan dengan merelokasi pedagang sayur mayur yang berjualan dibadan jalan kedalam area pasar. Guna memprogres Pasar Wonomulyo sebagai pusat perbelanjaan 'Marasa', Dinas Perindustrian Perdagangan, Koperasi dan Usaha Kecil Menengah (Disperindagkop dan UKM) terus melakukan pembenahan pada produk sentra industri rumah tangga, utamanya soal desain label dan kemasan. Namun terkendala teknis produksi cetak kemasannya.

Polewali Mandar adalah salah satu daerah yang terdapat di propinsi Sulawesi Barat yang juga merupakan Daerah Tingkat II di Sulawesi Barat jumlah penduduk dikabupaten Polewali Mandar pada tahun 2014 yang dihitung berdasarkan proyeksi penduduk. adalah 417.472 jiwa. Yang terdiri dari 203.981 laki-laki dan 213.491 perempuan. Ibukotanya adalah polewali yang berjarak $246 \mathrm{Km}$ dari kota Makassar Sulawesi Selatan. Pembagian administratif didaerah ini terdapat 16 kecamatan serta 144 desa dan 23 kelurahan, yang berada di daerah Polewali Mandar (Mandar, 2014).

Wonomulyo secara garis besar merupakan pusat perekominan di daerah Kabupaten Polewali Mandar meskipun bukan ibu kota. terbentuk sejak tahun 1937 saat masih berbentuk distrik. dibuka oleh transmigran jawa yang didatangkan oleh belanda pada bulan juli 1934. Wonomulyo awalnya bernama distrik colonie dan kemudian diganti menjadi Wonomulyo yang berarti hutan mulya. SMK YPPP Wonomulyo mitra PKM menjadi salah satu sekolah menengah kejuruan di Polewali Mandar terkhususnya Wonomulyo yang mampu menyiapkan lulusan yang siap berkompetensi dan berinovasi pada perkembangan kota Wonomulyo. SMK YPPP Wonomulyo didirikan pada tanggal 20 juli 1997 dan diprakarsai oleh bapak Drs. H. Hasan Sulur, seorang tokoh birokrasi senior yang telah banyak menorehkan kinerjanya di bidang pemerintahan. Selama selang 15 tahun mengabdi, kepercayaan masyarakat dari tahun ke tahun semakin meningkat, hal ini terbukti dari meningkatnya jumlah siswa dari tahun ke tahun, serta dukungan dari dunia usaha dan industry diiringi dengan dukungan dari instansi pemerintah. 


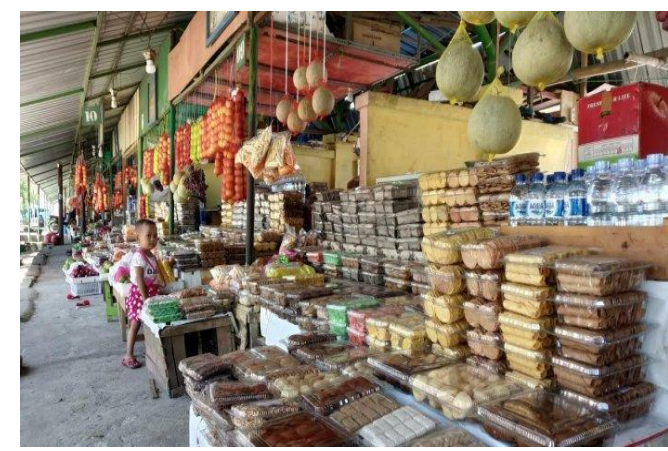

Gambar 1. Produk IRT di Kabupaten Polewali Mandar butuh cetak label dan kemasan (Sumber: tribunnews.com)

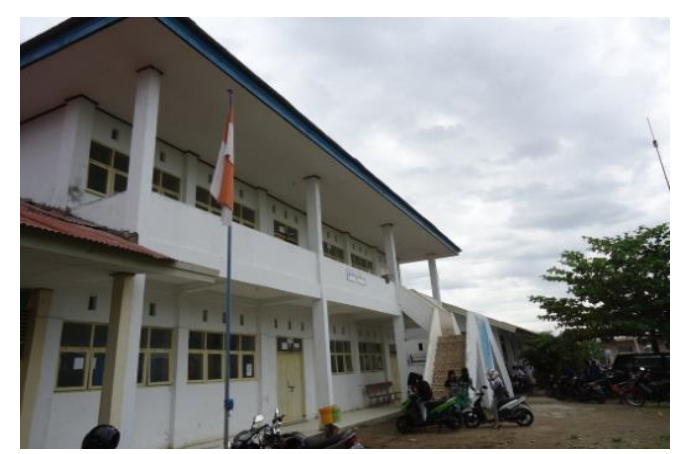

Gambar 2. Lokasi mitra PKM

Guna menunjang sarana pendidikan SMK YPPP Wonomulyo yang mandiri, di areal seluas 1500 M2, mempunyai fasilitas diantaranya, ruang teori, laboraterium komputer, laboraterium perakitan, laboraterium keperawatan, ruang seni, perpustakaan, koperasi siswa, hot spot area serta lapangan olahraga. SMK YPPP Wonomulyo selama ini aktif membina industri di Wonomulyo, oleh sebab itu dijadikan mitra agar terjadi transfer pengetahuan.

Cetak saring atau cetak sablon telah lama dikenal dan digunakan oleh bangsa Jepang sejak tahun 1664, abad ke-17. Ketika itu, Yuzensai Miyasaki dan Zisukeo Mirose mengembangkannya dengan menyablon kain kimono beraneka motif yang sebelumnya dibuat motif kimono dengan tulis tangan. Ternyata lebih menekan biaya sehingga kimono motif sablon mulai banyak digunakan oleh masyarakat Jepang (Tobroni, 2011).

Manfaat cetak sablon antara lain: membuat gambar pada tekstil; membuat poster, spanduk, logo, dan badge; membuat perlengkapan kantor; membuat gambar produk perusahaan dan banyak aplikasi lainnya, khususnya label kemasan.

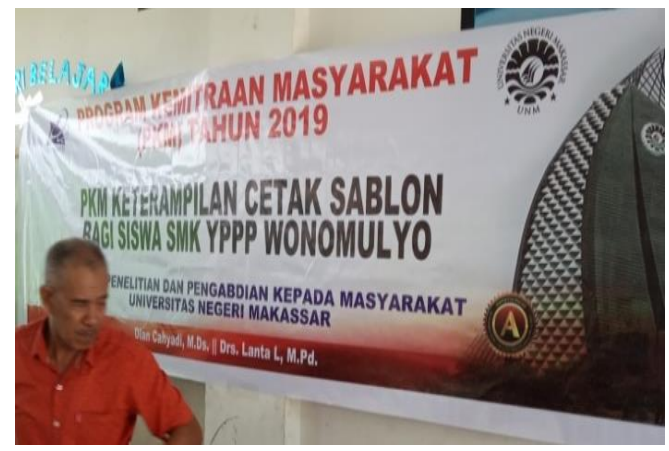

Gambar 3. Spanduk kegiatan

Beberapa permasalahan yang dihadapi oleh mitra yaitu mitra belum memiliki pengetahuan dan keterampilan cetak sablon dan cetak bentuk kemasan yang mempunyai tampilan menarik. Sehingga daya dukung industri kurang bersaing

\section{METODE PELAKSANAAN}

1. Agar mitra memiliki pengetahuan, maka metode yang digunakan adalah ceramah, demonstrasi, diskusi, dan tanya jawab.

2. Agar mitra terampil cetak sablon, maka metode yang digunakan adalah demonstrasi, diskusi, dan tanya jawab.

3. Agar mitra memiliki kemampuan meningkatkan kuantitas dan kualitas lanjutan, maka metode yang digunakan adalah demonstrasi, diskusi, tanya jawab, dan pendampingan mitra.

\section{PELAKSANAAN DAN HASIL KEGIATAN}

\section{A. Memperkenalkan Alat dan Peralatan Cetak Sablon}

Pada tahapan ini, tim pengabdi memperkenalkan kepada mitra alat-alat dan bahan-bahan yang akan digunakan. Setelah mitra mengenali dengan baik, maka dilanjutkan dengan memperkenalkan tahapan dan proses cetak sablon. 


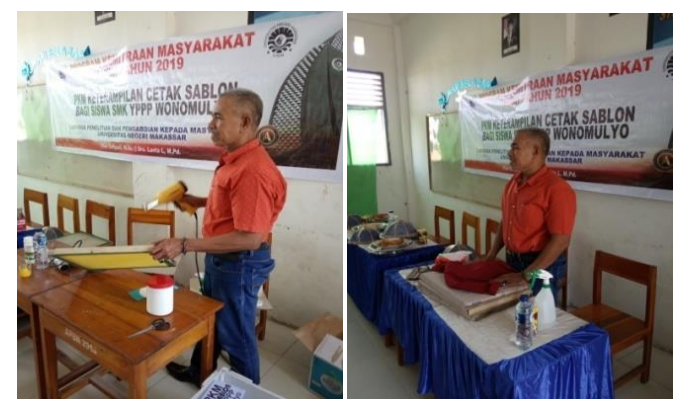

Gambar 4. Memperkenalkan alat, peralatan dan bahan
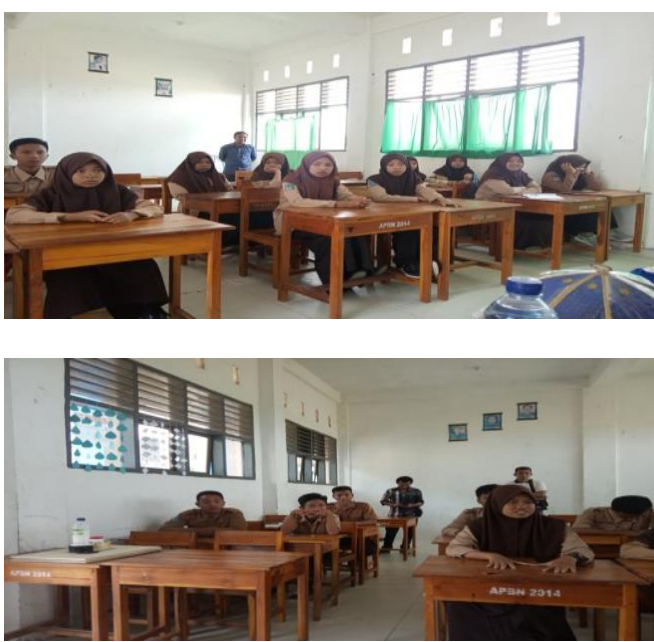

Gambar 5. Peserta PKM pelajar, guru, dan pemuda setempat

\section{B. Menjelaskan Proses dan Teknis Kerja}

Pada tahapan ini tim pengabdi menjelaskan tahapan dan teknis proses kerja. Setelah mitra mengetahui dan mengerti tujuan kegiatan dengan baik dan telah mengenali berbagai alat dan peralatan yang diguanakan, maka berikutnya dilanjutkan dengan kegiatan praktek langsung secara bertahap.

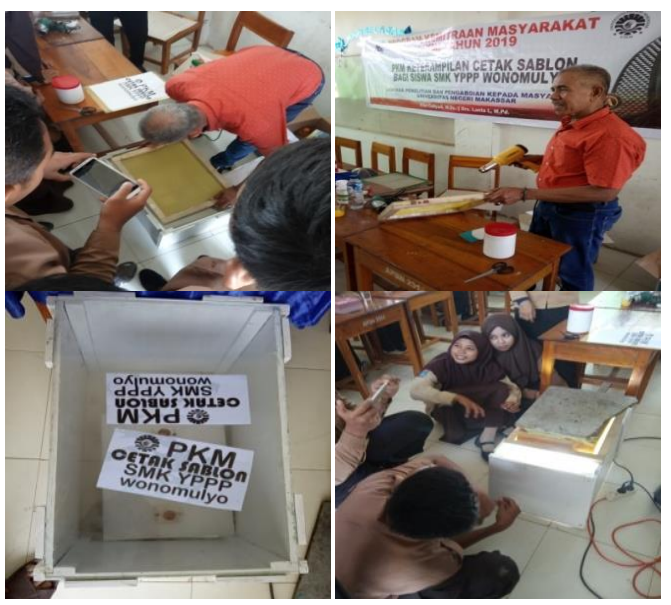

Gambar 6. Memperlihatkan tahapan dan proses kerja

\section{Melatih dan Mendampingi Mitra Memasang Asesoris}

Pada tahapan ini, tim pengabdi melatih dan mendampingi mitra melakukan transfer film yang menjadi obyek sablonan. Setelah mitra terampil, maka dilanjutkan dengan kegiatan pencucian hasil transfer film.

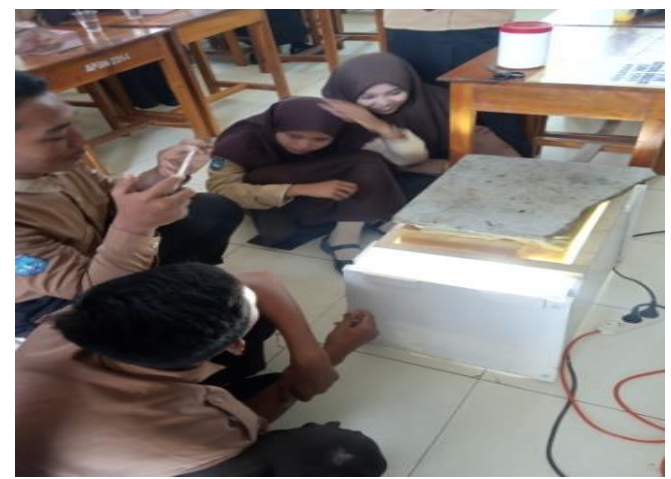

Gambar 7. Mitra sedang menunggu hasil transfer film

D. Mengevaluasi dan Memberikan Penjelasan Tambahan pada Setiap Tahapan Praktek Mitra

Pada tahapan ini, tim pengabdi melatih dan mendampingi mitra untuk memperbanyak produksi baju bodo yang memiliki asesoris dengan penampilan indah. Setelah mitra mengetahui dan terampil meningkatkan produksi baju bodo, maka berikutnya dilanjutkan dengan kegiatan meningkatkan kualitas produksi baju bodo.

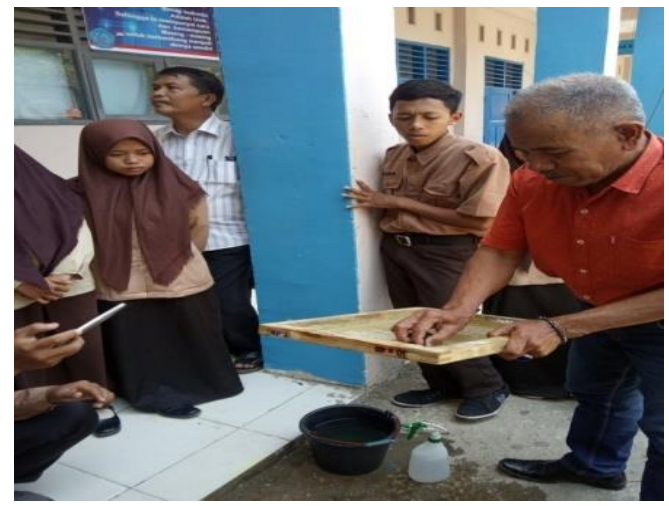

Gambar 8. Pengabdi langsung mengevaluasi hasil kerja mitra pada setiap tahapan prosesnya

\section{E. Melatih dan Mendampingi Mitra Membuat Analisis Usaha Cetak Sablon}

Pada tahapan ini, tim pengabdi melatih dan mendampingi mitra membuat analisis usaha cetak 
sablon dengan studi kasus pendampingan menghitung biaya cetak kemasan bagi IRT. Tujuan dari kegiatan ini adalah untuk menghitung dan menganalisis harga pokok produksi dan perbedaan perhitungan harga pokok produksi percetakan dengan menggunakan metode full costing. Metode penentuan harga pokok produksi adalah cara memperhitungkan unsur-unsur biaya ke dalam biaya produksi (Mulyadi, 2005). Penentuan harga pokok produksi terdapat dua metode yaitu metode full costing dan variable costing. Halim (Halim, Supomo, \& Kusafi, 2011) menyatakan bahwa perbedaan antara kedua metode yaitu full costing dan variabe costing berdasarkan perhitungan harga pokok produksi dapat dikatakan bahwa perbedaan antara kedua metode tersebut terletak pada perlakuan biaya overhead pabrik yang bersifat tetap. Dari kegiatan ini diharapkan mitra memiliki dasar kemampuan membuat analisis usaha secara sederhana.

\section{KESIMPULAN}

Hasil pelaksanaan kemitraan masyarakat dapat ditarik kesimpulan:

a. Mitra memiliki pengetahuan cetak sablon.

b. Mitra memiliki keterampilan cetak sablon.

c. Mitra memiliki pengetahuan manfaat memiliki keterampilan cetak sablon

d. Mitra memiliki pengetahuan cetak sablon bagi kemasan produk IRT

\section{DAFTAR PUSTAKA}

Halim, Supomo, \& Kusafi, S. (2011). Akuntansi Manajemen. Edisi Kedua Cetakan Pertama. . Yogyakarta: BPFE IKAPI.

Mandar, B. P. (2014). Buku Badan Pusat Statistik Kabupaten Polewali Mandar. Pemerintah Kabupaten Polewali Mandar.

Mulyadi. (2005). Akuntansi Biaya. Edisi Kelima Cetakan Ketujuh. . Yogyakarta : UPP.AMP.YKPN.

Tobroni, M. I. (2011). Teknik Sablon sebagai Media Apresiasi Karya Desain pada Tshirt. Humaniora Vol.2 No.1 , 169181. 